\title{
Coulomb Friction Applied to Analyze the Cutting Vibration of Tool on Workpiece
}

Chein-Shan Liu

Associate Professor, Department of Mechanical and Marine Engineering, National Taiwan Ocean University, Keelung, Taiwan, R.O.C.

Follow this and additional works at: https://jmstt.ntou.edu.tw/journal

Part of the Mechanical Engineering Commons

\section{Recommended Citation}

Liu, Chein-Shan (2001) "Coulomb Friction Applied to Analyze the Cutting Vibration of Tool on Workpiece," Journal of Marine Science and Technology. Vol. 9: Iss. 2, Article 7.

DOI: $10.51400 / 2709-6998.2442$

Available at: https://jmstt.ntou.edu.tw/journal/vol9/iss2/7

This Research Article is brought to you for free and open access by Journal of Marine Science and Technology. It has been accepted for inclusion in Journal of Marine Science and Technology by an authorized editor of Journal of Marine Science and Technology. 


\section{COULOMB FRICTION APPLIED TO ANALYZE THE CUTTING VIBRATION OF TOOL ON WORKPIECE}

\begin{abstract}
Keywords: Coulomb's friction, cutting vibration, abnormal stop, limit cycle, Hopf bifurcation.
\end{abstract}

Chein-Shan Liu*

\begin{abstract}
In this paper we study a single-degree-of-freedom model with the parallel presence of a linear spring and a Coulomb's contact friction device, the mass slider of which is mounted on the belt which running forward at a constant speed. We prove that no matter what the parameters are, the mass upon starting to slide never comes to stick on the belt. The oscillating amplitude of the slider is proportional to the belt running speed $v$, and is inverse proportional to the natural frequency $\omega$. In order to depress the vibration amplitude we may either decrease the belt running speed, increase the stiffness, or decrease the mass; however, the last two strategies may lead to high frequency oscillation of the tool. Increasing the friction bound $r_{y}$ gives no effect on the vibration amplitude, but increases the mean of vibration of the slider; conversely, increasing the stiffness makes the decreasing of the mean of vibration. We also investigate the friction behavior under the dependence of the friction force bound on relative speed, whose curve has negative slope when the relative speed is less than a critical value $v^{*}$. According to the qulitative analysis in the phase plane we give simple criteria of the parameters for the stable equilibrium point as well as for the stable limit cycle. When $v$ varies from $v>v^{*}$ to $v<v^{*}$, there undergoes a subcritical Hopf bifurcation of the long term behavior.
\end{abstract}

\section{INTRODUCTION}

Machine tool chatter is a well known self-excited vibration in metal cutting $[1,2]$, which in turns limits the productivity of the cutting process. The machine tool's and/or workpiece's structural dynamics and the cutting process interact to produce the conditions that lead to chatter. How to avoid chattering and how to depress its vibration amplitude are thus the main subjects in the material manufacturing and fabrication. In this paper we study a single-degree-of-freedom model with the parallel presence of a linear spring and a Coulomb's contact friction device, the mass slider of which is mounted on the belt which running forward at

Paper Received March 10, 2001. Author for Correspondence: Chein-Shan Liu. *Associate Professor, Department of Mechanical and Marine Engineering, National Taiwan Ocean University, Keelung, Taiwan, R.O.C. a constant speed $v$. A schematic drawing is shown in Fig. 1. This model includes four parameters, namely the mass $m$ of the slider, the stiffness $k$ of elastic support component, the friction bound $r_{y}$ between slider and belt (or the friction coefficient $\mu$ ), and the belt running speed $v$. It is a simple model to simulate the self-excited vibration behavior of tool-workpiece interaction due to contact friction.

Let $z$ denote the relative displacement of the slider to the belt,

$$
z=x-v t
$$

and so the relative velocity is

$$
\dot{z}=\dot{x}-v,
$$

where a superposed dot represents time differentiation. Assuming the friction law between the slider and the belt obeys the relation as shown in Fig. 2(a), where $r_{a}$ denote the contact friction force and $r_{y}$ is a constant friction bound independent of relative speed; hence, the equation of motion of the slider can be written as

$$
m \ddot{x}(t)+k x(t)+r_{a}(t)=0,
$$

where $m$ is the mass of the slider, and $k$ is the stiffness of the spring which connects to the slider through an

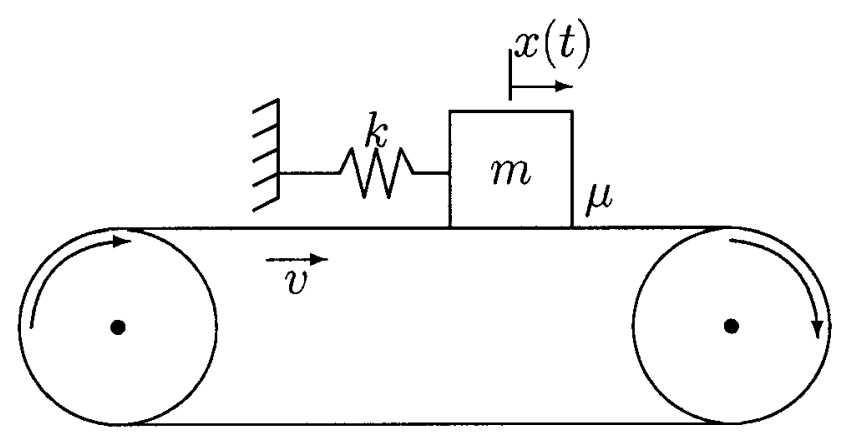

Fig. 1. The mass-spring-friction slider, where the friction refers to the Coulomb's dry friction between the mass and the belt. 
elastic support. In terms of $z$ the above equation is recast to

$$
m \ddot{z}(t)+k z(t)+r_{a}(t)=p(t), p(t):=-k v t,
$$

where $r_{a}$ is the friction force acting in a direction opposite to the direction of the relative motion, and $p(t)$ denotes external loading.

\section{MODELING FRICTION}

The following expression

$$
r_{a}= \begin{cases}r_{y} & \text { if } \dot{z}>0 \text { or } \dot{x}>v, \\ -r_{y} & \text { if } \dot{z}<0 \text { or } \dot{x}<v\end{cases}
$$

is usually employed to represent the two-valuedness of the Coulomb's dry contact friction. If the contact surfaces are horizontal on the earth ground, $r_{y}=\mu m g$, where $g$ is the acceleration of gravity and $\mu$ is the coefficient of friction. This formalism is correct but incomplete. In fact, the friction force $r_{a}$ may take any value between $r_{y}$ and $-r_{y}$ when $\dot{z}=0$; therefore, the following expression provides a more precise description,
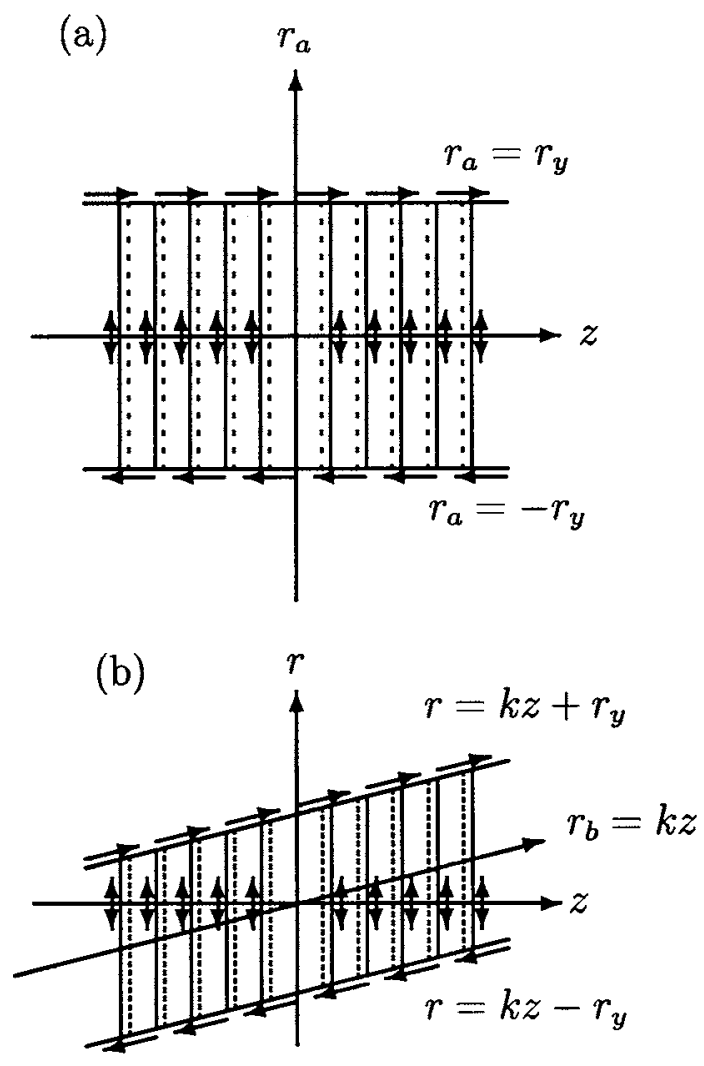

Fig. 2. (a) The relation of friction force $r_{a}$ and relative displacement $z$, (b) the relation of restoring force $r$ and relative displacement $z$.

$$
r_{a} \begin{cases}=r_{y} & \text { if } \dot{z}>0 \text { or } \dot{x}>v, \\ \in\left[-r_{y}, r_{y}\right] & \text { if } \dot{z}=0 \text { or } \dot{x}=v, \\ =-r_{y} & \text { if } \dot{z}<0 \text { or } \dot{x}<v .\end{cases}
$$

Nevertheless, the formalism (6), although correct, is not complete yet, since it still lacks a two-way relation between $\dot{z}$ and $r_{a}$. For completeness we need a sliding rule and a complementary trio as follows [3]:

$$
\begin{aligned}
& \dot{z}=\frac{\dot{\Lambda}}{r_{y}^{2}} r_{a}, \\
& \left|r_{a}\right| \leq r_{y}, \\
& \dot{\Lambda} \geq 0, \\
& \left|r_{a}\right| \dot{\Lambda}=r_{y} \dot{\Lambda},
\end{aligned}
$$

where $\dot{\Lambda}$ is the friction power, so that $\Lambda$ is the dissipated energy due to friction. According to this formulation the relation of $r_{a}$ and $z$ is schematically shown in Fig. 2 (a). More importantly, it depicts the relation of $r_{a}$ to $z$, not to $\dot{z}$ as the ones in Eqs. (5) and (6).

In view of Eq. (4), the restoring force $r(t)$ of the slider is decomposed as

$$
r=r_{a}+r_{b}
$$

with $r_{a}$ modeled by Eqs. (7)-(10) and $r_{b}$ by

$$
\dot{r}_{b}=k \dot{z}
$$

Thus, the relation between the restoring force function $r(t)$ and the relative displacement function $z(t)$ is described by Eqs. (7)-(12), which may be schematically illustrated in Fig. 2(b).

Equation (7) is a sliding rule, giving a two-way relation between the relative velocity $\dot{z}$ and the friction force $r_{a}$ via a proportional multiplier equal to the friction power $\dot{\Lambda}$ divided by the friction bound squared $r_{y}^{2}$. Equation (8) specifies an admissible range of the friction force. Equation (9) forbids a negative friction power, so that the relative velocity is either zero or in the same directional sense as that of friction force. Equation (10) allows either (the sticking phase) $\dot{\Lambda}=0$ or (the sliding phase) $\left|r_{a}\right|=r_{y}$. Equation (11) is the decomposition of the restoring force. Equation (12) is a linearly elastic law for the spring force.

\section{SLIDING AND STICKING}

\section{Two phases}

The complementary trios (8)-(10) imply that there 
are precisely two phases:

(i) $\dot{\Lambda}>0$ and $\left|r_{a}\right|=r_{y}$,

(ii) $\dot{\Lambda}=0$ and $\left|r_{a}\right| \leq r_{y}$.

For phase (i), $\dot{\Lambda}>0$ and $\left|r_{a}\right|=r_{y}$, so $\dot{\Lambda}=r_{a} \dot{z}>0$ by

Eq. (7). For phase (ii), $\dot{\Lambda}=0$ and $\left|r_{a}\right| \leq r_{y}$, so $\dot{z}=0$ by Eq. (7) and then $\dot{\Lambda}=r_{a} \dot{z}=0$. Therefore, the friction power formula

$$
\dot{\Lambda}=r_{a} \dot{z}
$$

holds for the two phases.

Phase (i) is nothing but the sliding phase, since $\dot{\Lambda}=r_{a} \dot{z}>0$ means $\dot{z} \neq 0$ so that the contact surfaces slide relative to each other and dissipation occurs due to friction between the sliding surfaces. Phase (ii) is obviously the sticking phase, since $\dot{\Lambda}=0$ drastically reduces Eq. (7) to $\dot{z}=0$, which indicates that the contact surfaces are sticking together. In the sliding phase, the sliding friction causes positive dissipation, while in the sticking phase the slider moves together with the belt and no dissipation occurs. Thus the history of the motion of the slider may be composed of a succession of contiguous time intervals, sliding-phase intervals being interlaced with sticking-phase intervals, but the time duration of a sticking-phase interval can be finite, infinite (permanent sticking), or zero.

\section{The sliding phase}

In this subsection and the next one we are going to derive the governing equations for the two phases, which will soon be seen to be expressed in terms of not only the relative displacement function $z(t)$ but also the restoring force function $r(t)$. In terms of $r(t)$, Eq. (4) changes to

$$
m \ddot{z}(t)+r(t)=p(t) .
$$

It follows from Eqs. (11) and (12) that

$$
r(t)=r\left(t_{i}\right)+r_{a}(t)-r_{a}\left(t_{i}\right)+k\left[z(t)-z\left(t_{i}\right)\right]
$$

for the two time instants $t$ and $t_{i}$. Substituting Eq. (14) for $r$ in Eq. (13), we have

$$
m \ddot{z}(t)+k z(t)+r_{a}(t)=p(t)-r\left(t_{i}\right)+r_{a}\left(t_{i}\right)+k z\left(t_{i}\right) .
$$

In a sliding-phase interval, $\left|r_{a}\right|=r_{y}$, so

$$
\text { SLIDING } r_{a}(t)=r_{a}\left(t_{i}\right) \text {, }
$$

where the initial time $t_{i}$ is chosen to be the start-to-slide time $t_{\text {slide }}$ of the sliding-phase interval under consideration. Hence, Eq. (15) can be simplified to

$$
\text { SLIDING } m \ddot{z}(t)+k z(t)=p(t)-r\left(t_{i}\right)+k z\left(t_{i}\right) .
$$

Including the restoring force on the right-hand side, this equation should be supplemented with

$$
\text { SLIDING } \quad r(t)=r\left(t_{i}\right)+k\left[z(t)-z\left(t_{i}\right)\right],
$$

which is Eq. (14) but with Eq. (16) been taken into account. Equations (17) and (18) together are the sliding-phase governing equations for $z(t)$ and $r(t)$. They are coupled together.

\section{The sticking phase}

In a sticking-phase interval, $\dot{\Lambda}=0$, so by Eqs. (7) and (12) we have

$$
\begin{array}{ll}
\text { STICKING } & r_{b}(t)=r_{b}\left(t_{i}\right), \\
\text { STICKING } & z(t)=z\left(t_{i}\right),
\end{array}
$$

where the initial time $t_{i}$ is now chosen as the start-tostick time $t_{\text {stick }}$ of the sticking-phase interval. In view of Eqs. (13) and (20) the restoring force is given by

$$
\text { STICKING } r(t)=p(t) \text {. }
$$

Equations (20) and (21) together are the sticking-phase governing equations for $z(t)$ and $r(t)$.

The above analysis shows that the slider is described by the linear equations (20) and (21) during the sticking phase, but governed by the linear equations (17) and (18) in the sliding phase. Hence it is a twophase linear system with a slide-stick switch.

\section{The slide-slide condition}

It is interesting to find the condition under which the time duration of a sticking-phase interval be zero. The transition (say at time $t$ ) from a sliding-phase interval to a sticking-phase interval of nonzero time duration is possible only if $|p(t)-k z(t)|<r_{y}$. Otherwise, a sliding-phase interval will continue to another sliding-phase interval with a sticking phase of zero time duration present in between the two sliding-phase intervals, but both the sliding-phase intervals are modeled by the same governing equations.

If at the time instant $t$

$$
|p(t)-k z(t)| \geq r_{y}
$$

the duration of the sticking-phase interval is zero, resulting in the slider moving from a sliding-phase inter- 
val to another sliding-phase interval. Therefore, Eq. (22) may be called the slide-slide condition.

\section{RESPONSES}

\section{Exact solution}

To input $p(t)=-k v t, z(t)$ in the sliding phase can be derived by solving Eq. (17),

$$
\begin{aligned}
z(t) & =z\left(t_{i}\right)+\frac{v}{\omega} \sin \omega\left(t-t_{i}\right)-\frac{r\left(t_{i}\right)}{k}\left[1-\cos \omega\left(t-t_{i}\right)\right] \\
& +v\left[t_{i} \cos \omega\left(t-t_{i}\right)-t\right],
\end{aligned}
$$

where $\omega:=\sqrt{k / m}$ is the natural frequency of the mass component, and $\dot{z}\left(t_{i}\right)$ is set to be zero by letting $t_{i}$ the start-to-slide time. Containing the restoring force on the right-hand side, Eq. (23) should be supplemented with Eq. (18). From Eqs. (23) and (1) it follows that

$$
\begin{gathered}
x(t)=x\left(t_{i}\right)+\frac{v}{\omega} \sin \omega\left(t-t_{i}\right)-\left[\frac{r\left(t_{i}\right)}{k}+v t_{i}\right] \\
{\left[1-\cos \omega\left(t-t_{i}\right)\right] .}
\end{gathered}
$$

In the sticking phase $z$ is simply given by Eq. (20), such that $x$ is as simple as

$$
x(t)=x\left(t_{i}\right)+v\left(t-t_{i}\right) .
$$

\section{The start-to-slide time}

Owing to the simplicity of the sticking-phase equations, the start-to-slide time $t=t_{\text {slide }}$, which is the end time of the preceding sticking-phase interval, can be determined exactly by solving

$$
\left|k v t+r_{b}\left(t_{i}\right)\right|=r_{y} .
$$

The resultant is

$$
t_{\text {slide }}=\frac{r_{y}-r_{b}\left(t_{i}\right)}{k v} \text {. }
$$

However, if $r_{b}\left(t_{i}\right) \geq r_{y}$ we let $t_{\text {slide }}=t_{i}$, which means that the mass already has the potential to slide at the initial time $t_{i}$.

\section{The start-to-stick time}

Since when a sticking-phase interval is switched on a sliding-phase interval is switched off at the same instant, the start-to-stick time $t_{\text {stick }}$ of the sticking-phase interval is the end time of the sliding phase, which is determined by solving $\dot{z}=0$ for $t=t_{\text {stick }}$ with $z(t)$ given by Eq. (23), that is,

$$
\dot{x}(t)=v \cos \omega\left(t-t_{i}\right)-\left[\frac{\omega r\left(t_{i}\right)}{k}+\omega v t_{i}\right] \sin \omega\left(t-t_{i}\right)=v .
$$
be

Therefore, the start-to-stick time $t_{\text {stick }}$ is found to

$$
t_{\text {stick }}=t_{i}+\frac{2 \pi}{\omega}
$$

At this time moment $t_{\text {stick }}, \dot{z}=0$ and $\dot{x}=v$, and thus the slider moves together with the belt. However, we shall prove that such co-moving has zero time duration.

\section{ABNORMAL STOP OF THE SLIDER}

Some results about the responses are shown in Fig. 3 , in which the parameters used were $m=5 \mathrm{kN} \mathrm{s}^{2} / \mathrm{cm}, k$ $=50 \mathrm{kN} / \mathrm{cm}, r_{y}=10 \mathrm{kN}$, and $v=5 \mathrm{~cm} / \mathrm{s}$. Stops with zero duration may be further classified into two types [3, 4]: normal stop and abnormal stop. The former occurs when the relative displacement reaches a local extremum and the mass reverses its direction of motion after
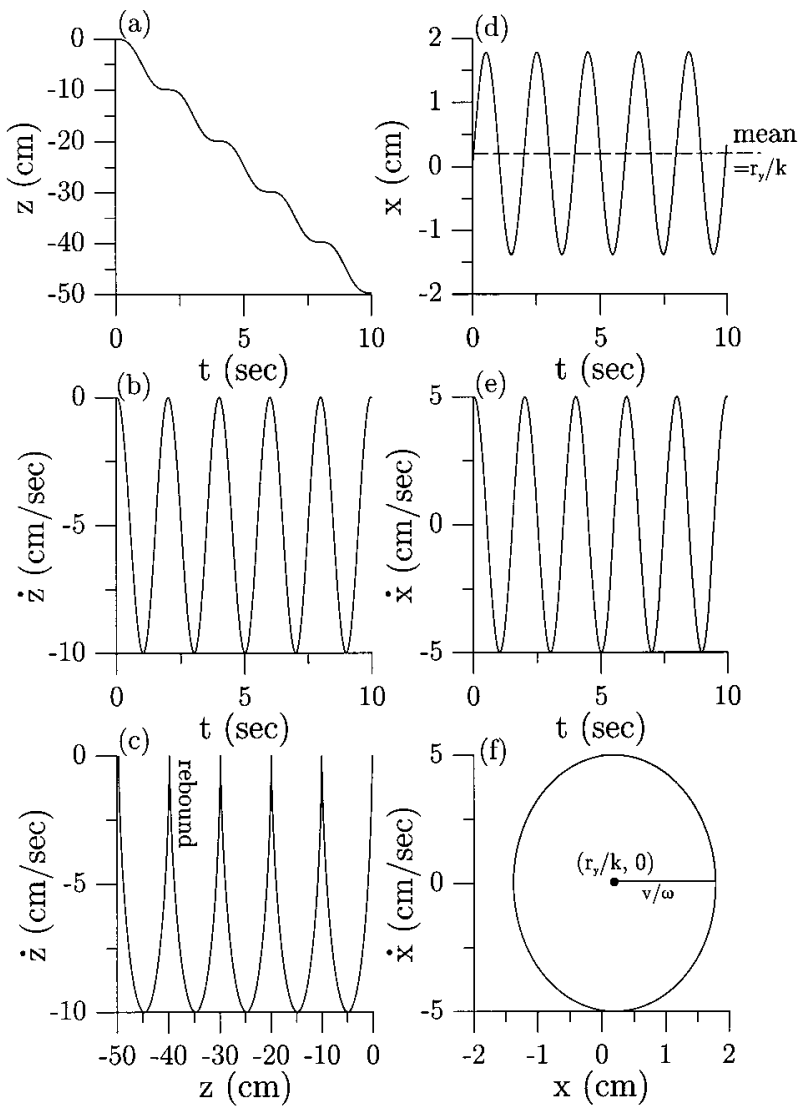

Fig. 3. Displaying a typical response in terms of (a) the time history of $z$, (b) the time history of relative velocity $\dot{z}$, (c) the phase plane $(z, \dot{z}),(\mathrm{d})$ the time history of $x$, (e) the time history of mass velocity $\dot{x}$, and (f) the phase plane $(x, \dot{x})$. 
a turning point. The criteria for normal stop is

$$
|p(t)-k z(t)| \geq r_{y} \text { and } r_{a}(t) \ddot{z}(t)<0
$$

at the time moment $t$ with $\dot{z}(t)=0$. The abnormal stop occurs when the relative displacement is large than its local minimum and, upon seperation, the mass moves in the same direction as its motion prior to the stop. The criteria for abnormal stop is

$$
|p(t)-k z(t)| \geq r_{y} \text { and } r_{a}(t) \ddot{z}(t)>0
$$

at the time moment $t$ with $\dot{z}(t)=0$. In Fig. 3 the phenomena of abnormal stop relative motion are shown with time history of $z(t)$ in Fig. 3(a), the time history of relative velocity $\dot{z}(t)$ in Fig. $3(\mathrm{~b})$, and the phase plane $(z, \dot{z})$ in Fig. 3(c). Simultaneously, the motion of the slider are shown with time history of $x(t)$ in Fig. 3(d), the time history of mass velocity $\dot{x}(t)$ in Fig. 3(e), and the phase curve $(x, \dot{x})$ in Fig. 3(f).

We shall prove that no matter what the system parameters are, the contact motion of slider and belt is of abnormal stop type with zero time duration. For simplicity we let all initial values to be zero in addition to $\dot{x}\left(t_{i}\right)=v$. Thus, we have

$$
\begin{aligned}
t_{\text {slide }} & =\frac{r_{y}}{k v}, \\
t_{\text {stick }} & =t_{\text {slide }}+\frac{2 \pi}{\omega} .
\end{aligned}
$$

At $t=t_{\text {stick }}$, we have

$$
\begin{aligned}
& z\left(t_{\text {stick }}\right)=\frac{-2 \pi v}{\omega}, \\
& r_{b}\left(t_{\text {stick }}\right)=\frac{-2 k \pi v}{\omega}, \\
& p\left(t_{\text {stick }}\right)=-k v\left(\frac{r_{y}}{k v}+\frac{2 \pi}{\omega}\right) .
\end{aligned}
$$

Substituting these equations into $\left|p(t)-r_{b}(t)\right|$ at $t=$ $t_{\text {stick }}$, we find that

$$
\left|-r_{y}\right| \geq r_{y} \text {. }
$$

It just fulfills the requirement of the first condition in Eq. (31) for the zero time duration of the stop, such that at the time moment $t=t_{\text {stick }}$ the slider never really sticks on the belt and a rebound of $z$ is shown in Fig. 3(c). It is of the abnormal stop type motion because the second condtion $r_{a}(t) \ddot{z}(t)>0$ in Eq. (31) at $t=t_{\text {stick }}$ is also fulfilled.

From Eqs. (24) and (28) it follows that

$$
\left(x-z\left(t_{i}\right)+\frac{r\left(t_{i}\right)}{k}\right)^{2}+\left(\frac{\dot{x}}{\omega}\right)^{2}=\left(\frac{v}{\omega}\right)^{2}+\left(\frac{r\left(t_{i}\right)}{k}+v t_{i}\right)^{2} .
$$

Substituting Eq. (32) for $t_{i}, r\left(t_{i}\right)=-r_{y}$, and $z\left(t_{i}\right)=0$ into the above equation, we obtain

$$
\left(x-\frac{r_{y}}{k}\right)^{2}+\left(\frac{\dot{x}}{\omega}\right)^{2}=\left(\frac{v}{\omega}\right)^{2} .
$$

Upon the sliding starts, the slider never sticks on the belt, and the phase trajectory $(x, \dot{x} / \omega)$ traces repeatedly on a circle with center $\left(r_{y} / k, 0\right)$ and radius $v / \omega$. In phase plane this single closed orbit is called limit cycle; see Fig. 3(f). From Eq. (24) it is clear that no matter what the initial condition is, the slider motion approaches the same periodic solution. This is a particular property of self-excited vibration system. For forced vibration system the vibration frequency is determined by the external forcing, but for self-excited system the vibration frequency is the natural frequency of its linearized system. For the free vibration of undamped system the vibration amplitude is determined by the initial conditions, but for self-excited system the vibration amplitude is determined by the system parameters and is independent to the initial conditions.

\section{FRICTION FORCE DEPENDING ON RELATIVE SPEED}

Instead of the constant friction bound used in the previous sections let us consider a more complicated law of friction force [5]:

$$
r_{a}(t)=r_{y} \operatorname{sgn}(\dot{z})-\alpha_{1} \dot{z}+\alpha_{2} \dot{z}^{3},
$$

where $\operatorname{sgn}$ is the signum function, i.e., $\operatorname{sgn}(\dot{z})=\dot{z} /|\dot{z}|$ if $\dot{z} \neq 0 . r_{y}, \alpha_{1}$ and $\alpha_{2}$ are three experimentally determined constants. In Fig. 4 the curve is plotted with $r_{y}=10 \mathrm{kN}$, $\alpha_{1}=1 \mathrm{kN} \mathrm{s} / \mathrm{cm}$ and $\alpha_{2}=0.01 \mathrm{kN} \mathrm{s} / \mathrm{cm}^{3}$. It shows that the friction force-speed curve may have negative slope when the relative speed is less than a critical value $v^{*}$. It is known that the negative slope of the curve is responsible for the energy that is supplied to the vibration, and thus may render self-excited vibration in the course of contact friction [6].

Substituting Eq. (40) for $r_{a}$ into Eq. (3), we obtain

$$
\begin{aligned}
& m \ddot{x}(t)+k x(t)+r_{y} \operatorname{sgn}(\dot{x}-v)-\alpha_{1}(\dot{x}-v)+\alpha_{2}(\dot{x}-v)^{3} \\
& =0
\end{aligned}
$$

where $\dot{z}$ is replaced by $\dot{x}-v$ in view of Eq. (1). The above equation can be written as

$$
\frac{d}{d t}\left[\begin{array}{l}
x \\
y
\end{array}\right]=\left[\begin{array}{c}
y \\
\frac{1}{m}\left[r_{y} \operatorname{sgn}(v-y)-\alpha_{1}(v-y)+\alpha_{2}(v-y)^{3}-k x\right]
\end{array}\right],
$$


where $y:=\dot{x}$. Let $\dot{x}=0$ and $\dot{y}=0$ we obtain the equilibrium point

$$
\left(x_{0}, y_{0}\right)=\left(\frac{r_{y}-\alpha_{1} v+\alpha_{2} v^{3}}{k}, 0\right) \text {. }
$$

Substituting the equilibrium point into the Jacobian matrix of the flow field, we get

$$
\mathbf{J}=\left[\begin{array}{cc}
0 & 1 \\
-\omega^{2} & \frac{1}{m}\left(\alpha_{1}-3 \alpha_{2} v^{2}\right)
\end{array}\right] .
$$

The eigenvalues of $\mathbf{J}$ determine the stability of the equilibrium point $\left(x_{0}, y_{0}\right)$. The characteristic equation for the eigenvalues $\lambda$ is

$$
\lambda^{2}-q \lambda+\omega^{2}=0
$$

where

$$
q:=\frac{\alpha_{1}-3 \alpha_{2} v^{2}}{m} .
$$

When $q<0$ the equilibrium point is stable; otherwise, it is unstable. In the later we shall give three examples to disclose such behavior.

According to Eq. (40) the governing equation of the relative displacement in the sliding phase is given by

$$
m \ddot{z}(t)-\alpha_{1} \dot{z}(t)+\alpha_{2} \dot{z}^{3}(t)+k z(t)=p(t)-r\left(t_{i}\right)+k z\left(t_{i}\right),
$$

where

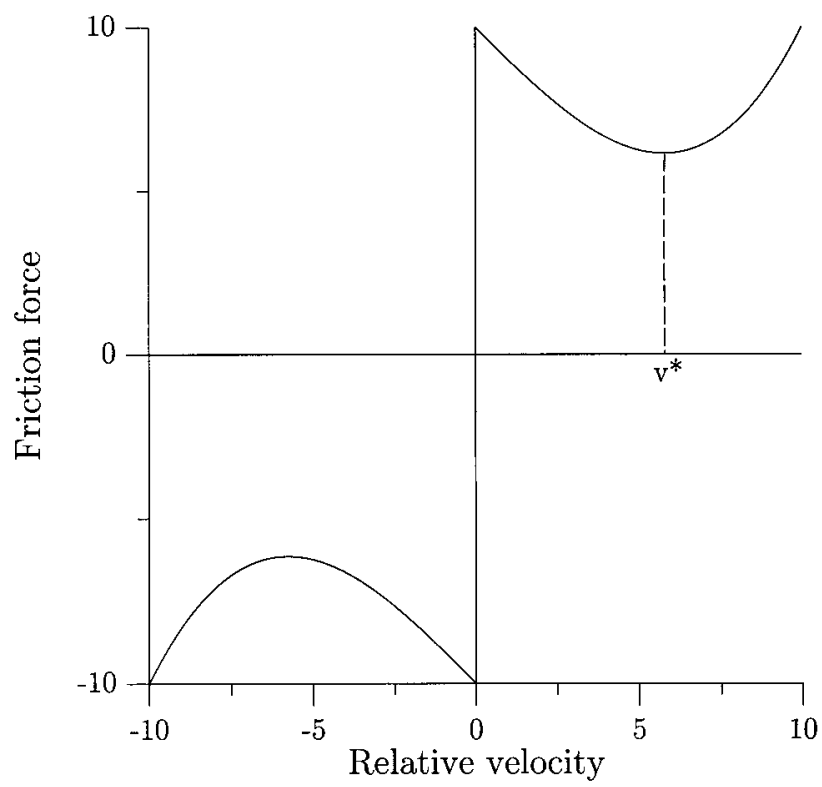

Fig. 4. The friction force depends on relative speed through the relation $r_{c}$ $=r_{y} \operatorname{sgn}(\dot{z})-\alpha_{1} \dot{z}+\alpha_{2} \dot{z}^{3}$, where $\alpha_{1}$ and $\alpha_{2}$ are experimentally determined constants.

$$
r(t)=r\left(t_{i}\right)+k\left[z(t)-z\left(t_{i}\right)\right]-\alpha_{1} \dot{z}(t)+\alpha_{2} \dot{z}^{3}(t) .
$$

In order to integrate Eq. (47), we appeal to the numerical scheme developed by Liu [7].

$$
\begin{aligned}
& u_{1}^{j+1}=u_{1}^{j}+\frac{2 \tau\left\|\mathbf{u}^{j}\right\|^{2}+2 \tau^{2} \mathbf{f}^{j} \cdot \mathbf{u}^{j}}{\left\|\mathbf{u}^{j}\right\|^{2}-\tau^{2}\left\|\mathbf{f}^{j}\right\|^{2}} \mathrm{f}_{1}^{j}, \\
& u_{2}^{j+1}=u_{2}^{j}+\frac{2 \tau\left\|\mathbf{u}^{j}\right\|^{2}+2 \tau^{2} \mathbf{f}^{j} \cdot \mathbf{u}^{j}}{\left\|\mathbf{u}^{j}\right\|^{2}-\tau^{2}\left\|\mathbf{f}^{j}\right\|^{2}} \mathrm{f}_{2}^{j},
\end{aligned}
$$

where $\tau=\Delta t / 2, u_{1}^{j}:=u_{1}(j \Delta t)$ and so on, and

$$
\begin{aligned}
& f_{1}(t)=u_{2}(t), f_{2}(t)=\frac{1}{m}\left[p(t)-r\left(t_{i}\right)+k u_{1}\left(t_{i}\right)-k u_{1}(t)\right. \\
& \left.+\alpha_{1} u_{2}(t)-\alpha_{2} u_{2}^{3}(t)\right] \\
& u_{1}(t)=z(t)+a, u_{2}(t)=\dot{z}(t), \\
& \|\mathbf{u}(t)\|^{2}=u_{1}^{2}(t)+u_{2}^{2}(t),\|\mathbf{f}(t)\|^{2}=f_{1}^{2}(t)+f_{2}^{2}(t), \\
& \mathbf{f}(t) \cdot \mathbf{u}(t)=f_{1}(t) u_{1}(t)+f_{2}(t) u_{2}(t) .
\end{aligned}
$$

$a$ is a constant to avoid the zero denominator in Eqs. (49) and (50). If $u_{1}(t)$ and $u_{2}(t)$ were calculated, $x(t)=z(t)+$ $v t=u_{1}(t)-a+v t$ and $\dot{x}(t)=\dot{z}(t)+v=u_{2}(t)+v$ follow straightforward.

By employing the above scheme we have calculated three type responses. In Fig. 5 we let $\alpha_{1}=1 \mathrm{kN} \mathrm{s} /$ $\mathrm{cm}$ and $\alpha_{2}=0.05 \mathrm{kN} \mathrm{s}^{3} / \mathrm{cm}^{3}$ and the other parameters are the same as the ones used in Fig. 3. For this case we have $q=-0.55 \mathrm{~s}^{-1}$, such that the equilibrium point is stable. Because the eigenvalues are complex the orbit as shown in Fig. 5(c) is spiraled into the equilibrium point. For the second case we let $\alpha_{1}=1 \mathrm{kN} \mathrm{s} / \mathrm{cm}$ and $\alpha_{2}=1 / 75 \mathrm{kN}$ $\mathrm{s}^{3} / \mathrm{cm}^{3}$, such that $q=0$ and the equilibrium point is neutral stable. After a long time elapsed the orbit tends to a small size periodic orbit as shown in Fig. 5(f). For the third case we let $\alpha_{1}=1 \mathrm{kN} \mathrm{s} / \mathrm{cm}$ and $\alpha_{2}=0.01 \mathrm{kN} \mathrm{s}^{3} /$ $\mathrm{cm}^{3}$, such that $q=0.05 \mathrm{~s}^{-1}$ and the equilibrium point is unstable, and instead of we have a stable limit cycle as shown in Fig. 5(i). This steady slide-stick vibration is different from the ones in Fig. 3, of which $\alpha_{1}=\alpha_{2}=0$ leads to a neutral stable equilibrium point and a nonsticking limit cycle. The limit cycles in Figs. 3(f) and 5 (i) almost have the same size; the vibration amplitude seems to be dominated by $v / \omega$. In order to obtain a stable limit cycle a simple criterion is given as follows:

$$
\alpha_{1}-3 \alpha_{2} v^{2} \geq 0
$$

Let us denote the critical speed of the belt by $v^{*}$ : $=\sqrt{\alpha_{1} /\left(3 \alpha_{2}\right)}$ as shown in Fig. 4, which gives the minimum friction force bound at $v^{*}$. It indicates that 
when $v>v^{*}(q<0)$ the slider motion tends to a stable equilibrium point, and when $v<v^{*}(q>0)$ the slider motion tends to a stable limit cycle. Thus, we say that when $v$ varies from $v>v^{*}$ to $v<v^{*}$ there undergoes a subcritical Hopf bifurcation [8, 9].

\section{CONCLUSIONS}

Even the model employed to simulate the friction pair behavior of tool and workpiece on the cutting process was too simple, it may let us capture the main influence factors for vibration in such interaction. First we have proved that no matter what the parameters are, the mass upon starting to slide never comes to stick on the belt. In terms of the relative displacement we call such stop abnormal. Then according to Eq. (39) we drew the following conclusions. The oscillating amplitude of the slider was proportional to the speed $v$ of the running belt, and was inverse proportional to the natural frequency $\omega$. In order to depress the vibration amplitude we could decrease the belt running speed, increase the stiffness or decrease the mass of the tool; however, the last two strategies may induce high frequency oscil-
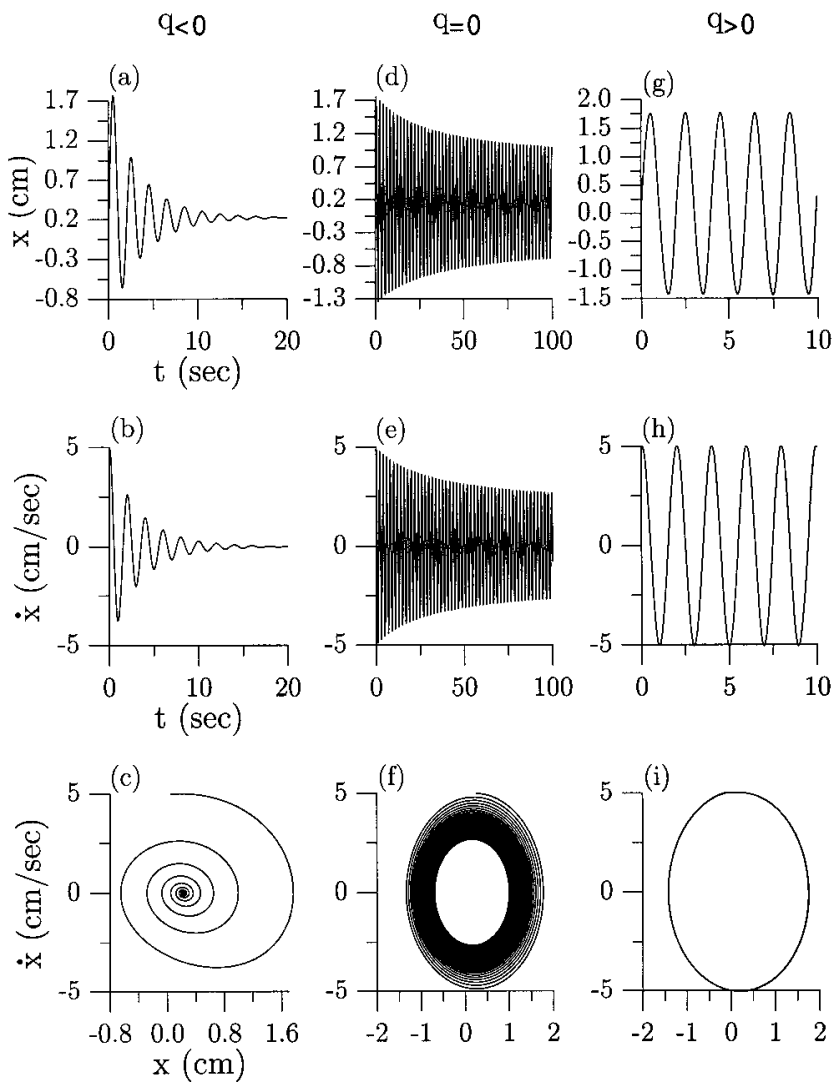

Fig. 5. Displaying the responses of the time history of $x$, the time history of mass velocity $\dot{x}$, and the phase plane $(x, \dot{x})$ for three cases with $q<$ 0 in (a)-(c), $q=0$ in (d)-(f), and $q>0$ in (g)-(i). lation of the tool. Increasing the friction bound $r_{y}$ (or the friction coefficient $\mu$ ) gave no effect on the vibration amplitude, but increased the mean of vibration. For the speed-dependent friction force law, we have investigated its friction behavior according to the qulitative analysis in the phase plane. The formula (51) give a simple criterion for the appearance of stable limit cycle. We prove that when $v$ varies from $v>v^{*}$ to $v<v^{*}$ there undergoes a subcritical Hopf bifurcation of the behavior. The size of limit cycle is determined mainly by $v / \omega$, and is less dependent on the speed-related coefficients $\alpha_{1}$ and $\alpha_{2}$.

\section{REFERENCES}

1. Ibrahim, R. A., "Friction-induced vibration, chatter, squeal, and chaos. Part I: mechanics of contact and friction, Part II: dynamics and modeling," Appl. Mech. Rev., Vol. 47, pp. 209-253 (1994).

2. Moon, F. C. ed., Nonlinear dynamics and chaos in manufacturing processes, John Wiley \& Sons, New York, 1998.

3. Hong, H.-K. and Liu, C.-S., "Coulomb friction oscillator: modelling and responses to harmonic loads and base excitations," J. Sound Vib., Vol. 229, pp. 1171-1192 (2000).

4. Makris, N. and Constantinou, M. C., "Analysis of motion resisted by friction: I. Constant Coulomb and linear Coulomb friction," Mech. Struct. Mach., Vol. 19, pp. 477-500 (1991).

5. Alifov, J. R. and Frolov, K. V., "Investigation of selfexcited oscillations with friction under conditions of parametric excitation and limited power of energy source, "Mekhanika Tverdogo Tela, Vol. 14, pp. 25-33 (1979).

6. Tondol, A., Self-excited Vibrations, Monograph No.9, National Res. Institute for Machine Design, Bechovice, 1970.

7. Liu, C.-S., "Cone of non-linear dynamical system and group preserving schemes," Int. J. Non-Linear Mech., Vol. 36, PP. 1047-1068 (2001).

8. Liu, C.-S., "Intermittent transition to quasiperiodicity demonstrated via a circular differential equation," Int. J. Non-Linear Mech., Vol. 35, pp. 931-946 (2000).

9. Moiola, J. L. and Chen, G., Hopf Bifurcation Analysis: A Frequency Domain Approach, World Scientific, Singapore, 1996. 


\title{
應用庫倫摩擦分析刀具與工件的切 削自振
}

\author{
劉進賢
}

國立臺灣海洋大學機械與輪機工程學系

摘 要

本文以單自由度彈簧庫倫摩擦子並聯模式, 探 討滑塊在恆速皮輪驅動下的振動行爲。這個模式包含 四個參數: 滑塊質量 $m$ 、彈簧勁度 $k$ 、摩擦係數 $\mu$ 及皮 輪驅動速率 $v$; 可做爲刀具與工件切削摩擦自振的簡 化模型。本文證明不管參數爲何, 滑塊一但開始滑動 就不再秥住皮輪, 而與皮輪有相對運動。滑塊振幅正 比於皮輪驅動速率 $v$, 但反比於自然頻率 $\omega$ 。爲了減 低滑塊振幅, 可採取減低皮輪驅動速率, 增加彈簧勁 度, 或提高滑塊質量等方式; 但後兩個策略可能造成 高頻振動。增加摩擦係數並不影響滑塊振幅, 但會造 成振動的平均值增加; 反之, 增加彈簧勁度可減低振 動的平均值。本文亦探討摩擦力和速率相關時的滑塊 振動行爲。經由相平面的定性分析, 給出穞定平衡點 的參數條件及稳定極限環的參數條件。極限環的大小 主要決定於 $v / \omega$, 而與速率相關的參數影響較小。 